\title{
XXXIX. Notices of the results of the labours of continental chemists
}

\author{
Messr. W. Francis \& Messr. H. Croft
}

To cite this article: Messr. W. Francis \& Messr. H. Croft (1841) XXXIX. Notices of the results of the labours of continental chemists, Philosophical Magazine Series 3, 19:124, 278-285, DOI: 10.1080/14786444108650417

To link to this article: http://dx.doi.org/10.1080/14786444108650417

册 Published online: 01 Jun 2009.

Submit your article to this journal $₫$

Џ Article views: 2

Q View related articles $₫$ 
XXXIX. Notices of the Results of the Labours of Continental Chemists. By Messrs. W. Francis and H. Croft.

[Continued from p. 195.]

Ners Method of determining Nitrogen.

TN a letter addressed by Berzelius to Prof. Erdmann, and published in the Journ.f. Prakt. Chem. for June 15th, 1841, we find the following important notice:- "On preparing the interesting memoir of Dumas on the decomposition of organic substances, by the action of the hydrate of potash, for my Annual Report, it occurred to me that nitrogenous bodies should, when so treated, give off the whole amount of their nitrogen as ammonia, which may be received in muriatic acid just in the same manner as carbonic acid in a solution of potash, and weighed as ammonio-chloride of platinum. I am following up this idea with M. Plantamour. To guard against the formation of cyanogen, we have commenced with compounds of cyanogen, which give ammonia just as well as salammoniac and lime. If, indeed, all should succeed according to the present appearances, what a valuable and easy control in determinations of nitrogen we shall thus obtain! We make the experiments in the same way as the usual organic analyses, and pass the vapours over a strongly-heated mixture of the hydrate of potash and hydrate of lime, to decompose such bodies as, for instance, anil $\left(\mathrm{C}^{12} \mathrm{H}^{8}+\mathrm{N} \mathrm{H}^{3}\right)$."

\section{Nitrurets.}

On exposing the white precipitate to a gradually increasing heat, a vast quantity of ammonia first passes over without any trace of nitrogen gas, after which perchloride of mercury-ammonia, and ammonia are evolved; and a red body remains in the retort, which decomposes at a temperature above $360^{\circ}$ into protochloride of mercury, mercury and nitrogen. This red body is obtained purest when the heating is continued in a metallic bath until some protochloride of mercury has formed. It consists of crystalline scales, and has quite the appearance of the crystalline peroxide of mercury. It is insoluble in water, not affected by aqueous alkalies, even at the boiling point of the liquid. The compound may be boiled with dilute and concentrated nitric acid, and with rather concentrated sulphuric acid, without being decomposed or dissolved, which takes place, however, when it is boiled with concentrated sulphuric acid, or with hydrochloric acid: no gas is evolved. Heated beyond the boiling point of mercury, nitrogen escapes; mercury and protochloride of mercury are sublimed. Several experiments were made to determine these three bodies; ac- 
cording to which the compound consists of perchloride of mercury with nitruret of mercury, $2 \mathrm{Hg} \mathrm{Cl}+\mathrm{Hg}^{3} \mathrm{~N}$. Prof.

Mitscherlich, by whom the above researches have been made, did not succeed in isolating the nitruret of mercury. This has been effected by Plantamour. It explodes violently, equalling, if not surpassing, in this respect the iodide of nitrogen, but is by far less sensitive. It forms a dark brown powder; decomposed with oxide of copper after the manner of an organic analysis, it gives no water, but only nitrogen and mercury; the true discoverer of nitrurets is, however, Schrötter, to whose experiments we shall presently return. Mitscherlich concludes, from the composition of the chloronitruret of mercury (Quecksilberstickstoffchlorid), that the white precipitate does not consist of one atom of the perchloride of mercury

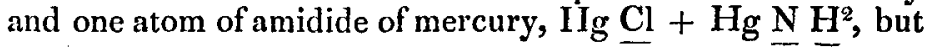
of three atoms of both substances, $3 \mathrm{Hg} \mathrm{Cl}+3 \overline{\mathrm{Hg}} \overline{\mathrm{N} \mathrm{H}}$; as, on heating, two atoms of ammonia and one of perchloride of mercury are separated $*$. The perbromide of mercury acts in the same manner as the perchloride towards ammonia, giving off, on being heated, bromide of mercury-ammonia and ammonia, and bromo-nitruret of mercury remains behind. The mercury behaves in these compounds in the same way as potassium to ammonia; the olive-coloured body which is obtained by the action of potassium on dry gaseous ammonia is amidide of potassium, $\left(3 \mathrm{~K} . \mathrm{N} \mathrm{H}^{2}\right)$; and the graphite-like substance, which is formed by exposing the amidide of potassium to heat, whereby ammonia is set free, contains nitruret of potassium, $\mathrm{K}^{3} \mathrm{~N}$.

Schrötter, to whose experiments we have above alluded, has succeeded in preparing several nitrurets, of which he has given a description, and their mode of preparation, analysis and properties, from which we extract the following:-Metallic copper is not affected by being treated with dried ammoniacal gas; but, when well-dried gaseous ammonia is passed over oxide of copper, situated in a glass tube three feet long, and the anterior portion of the tube where the gas enters gently heated, formation of water and evolution of nitrogen take place, without any reduction of the oxide being perceptible. When the under portion of the tube is more strongly heated, reduction ensues with violent disengagements of nitrogen and formation of water. In the portion of the tube gently heated, the oxide of copper is found to be partially converted into a green powder; while, in that portion subjected to higher tem-

* See Dr. Kane's paper, Phil. Mag., August 1840, S. 3, vol. xvii. p. 125. 
perature, only reduced copper occurs. When the green powder is heated over a spirit-lamp, a beautiful combustion appears before red heat; at the same time it is converted with violent disengagement of nitrogen into metallic copper : this indicates that the green powder is a combination of nitrogen with copper, which is confirmed by numerous experiments. The formation of the nitruret of copper takes place long before the boiling point of linseed oil, and, in fact, at $250^{\circ} \mathrm{C}$., while the reduction of the oxide of copper, by means of hydrogen, only takes place at the boiling point. The degree of division of the oxide is of much importance, and it is best to employ an oxide prepared by precipitating a hot solution of the nitrate of copper with caustic potash, and boiling. Even with this precaution it is difficult to prepare a nitruret of copper perfectly fiee from oxide; for, after the action of ammonia has continued for about eight hours, all formation of water ceases; the powder must then be well shaken, which must be often repeated, and towards the end of the operation triturated several times in a mortar. To produce twenty grammes of nitruret of copper, it is requisite to continue the action of ammonia during 120 hours. The hydrate or carbonate of copper cannot be employed with the same advantage as the oxide, as they become heated in contact with ammonia, and the temperature rises so high that the nascent nitruret is immediately decomposed. The nitruret of copper is a somewhat blackish, fine powder (the green powder contains still undecomposed oxide of copper), which, at a temperature of about $300^{\circ}$, becomes decomposed, whilst evolving a beautiful red light, into copper and nitrogen, which is mixed with nitric oxide, if the combination still contain some oxide. In carbonic acid, and in ammoniacal gas, it is decomposed at a higher, in oxygen, at a lower temperature, than in atmospheric air. It is not decomposed by pressure or friction. Acids decompose it; brought into contact with sulphuric acid, a violent disengagement of nitrogen ensues, and the copper remains behind in a metallic state. Acids which dissolve the copper, as nitric acid, act far more violently. It is impossible to free it entirely from adherent ammonia. The analysis was made according to the method generally aclopted for organic nitrogenous substances. The amount of copper was determined by dissolving a portion of the combination in nitric acid, and converting the nitrate into oxide of copper. 'The results obtained agree exceedingly well with the formula $\mathrm{N} \mathrm{Cu}^{3}$.

[* See Prof. Grove's paper on some electro nitrogurets, in the present volume, pp. 100, 103: see also, Phil. Mag. Second Series, vol. iv. p. 155; vol. vi. p. 147.-EDIT.] 
Liebig observed, that on heating the bichromate of the perchloride of chromium with ammonia, or the chloride of chromium in gaseous ammonia, metallic chromium is obtained; the metal obtained, according to these two methods, exhibits, however, very different properties; the first being a black powder, which, under the steel, acquires a metallic lustre, while the latter has a dull chocolate-brown colour. 'This difference in the properties induced M. Schrötter to examine them more accurately: he found, that on heating the brown powder in a combustion-tube, from which atmospheric air had been expelled by means of carbonic acid, a beautiful incandescence ensued, accompanied by a violent disengagement of gas, which proved to be nitrogen mixed with nitric oxide. Another experiment showed that the substance contained no hydrogen; it is, therefore, nitruret of chromium. Its composition is represented by the formula $\mathrm{N}^{5} \mathrm{Cr}^{2}$. It is impossible to free it entirely from ammonia. The brown powder is a mixture of the nitruret with the oxide of chromium, to obtain it free from which it must be prepared in the following manner:-The chloride of chromium is heated in an atmosphere of hydrochloric gas, until it is anhydrous; it has then acquired a beautiful peach-red colour, and is deposited in crystalline laminæ in the upper part of the tube. On trenting it with ammonia all contact with oxygen must be carefully avoided. Thus prepared, the nitruret of chromium is black, and has all the properties of the body prepared after the other method. (Mitscherlich in Poggendorff's Annalen, vol. xlix. p. 407; Berzelius in Journ. für Prakt. Chem. vol. xxiii. p. 230; and Schrötter in Annal. der Chem. und Pharm. vol. xxxvii. p. 129.)

Action of Ammonia on glowing Charcoal; formation of Prussic Acid, \&c.

In a notice published in Liebig's Ann. der Chem. und Pharm. vol. xxxviii. p. 69 , M. Kuhlmann advances the following positions, to which he has been led by experiments on the properties of spongy platinum:-1. All volatile nitrogenous compounds can, when mixed with air, oxygen, or an oxygenous gas, be converted by this means into nitric acid or hyponitric acid: 2, the same compounds produce with hydrogen, or an hydrogenous gas, ammonia: 3, mixed with hydrocarbons, or when the nitrogen compound contains hydrogen with carbonic oxide, they produce prussic acid or the prussiate of ammonia. In repeating the experiment described by Clouet, viz. the production of prussic acid by the action of ammonia on incandescent charcoal, M. Kuhlmann found it to succeed perfectly, the prussiate of ammonia is obtained however, the free 
acid being decomposed at the temperature at which the action takes place; at the same time quadricarburet of hydrogen is evolved. The decomposition may be expressed by the formula $3 \mathrm{C}+2 \mathrm{~N}^{2} \mathrm{H}^{6}=\mathrm{N}^{2} \mathrm{C}^{2} \mathrm{H}^{2}, \mathrm{~N}^{2} \mathbf{H}^{6}+\mathrm{CH}^{4}$. The energetic action of charcoal on ammonia may be turned to account in preparing anhydrous prussic acid. For this purpose dried ammonia is passed through a porcelain tube containing small pieces of red-hot charcoal; the escaping gases, containing much prussiate of ammonia, are conveyed into dilute sulphuric acid, warmed to about $50^{\circ}$; the ammonia is detained by the sulphuric acid, and only prussic acid escapes, which is condensed in a vessel surrounded by a frigorific mixture. The acid thus obtained is quite as pure as that from the decomposition of cyanide of mercury by means of hydrochloric acid. This action of carbon with ammonia may also be employed in the preparation of the ferrocyanide of potassium; the vapour of the prussiate of ammonia is passed into a solution of caustic potash, in which the hydrate of the protoxide of iron is suspended.

Similar experiments on the action of ammonia on red-hot charcoal have been published by M. Langlois in the Annales de Chim. et de Phys. 3ième Sér. t. i. p. 117, which agree with the above, with the exception that the gas which escapes at the formation of the prussiate of ammonia, is stated to contain neither nitrogen nor carburetted hydrogen, but to be pure hydrogen. To explain the decomposition M. Langlois adopts the notion, that one equiv. of ammonia, $\mathrm{N}^{2} \mathrm{H}^{6}$, becomes, on contact with incandescent charcoal, $\mathrm{N}^{2} \mathrm{H}^{2}+\mathrm{H}^{4}$; the two equiv. of hydrogen are then replaced by two equiv. carbon to form prussic acid, which immediately enters into combination with one equiv. of undecomposed ammonia; a portion of the bydrogen of the ammonia being replaced by carbon exactly as the oxygen of the metallic oxides by chlorine, when exposed with the latter to a high temperature. 0.114 of the salt gave 0.340 cyanide of silver, corresponding to 0.068 prussic acid, which gives the formula $\mathrm{N}^{2} \mathrm{H}^{6}+\mathrm{C}^{2} \mathrm{~N}^{2} \mathrm{H}^{2}$.

\section{Double Cyanurets of Zinc roith Alkalies and Earths.}

Samselius has found that these combinations may likewise be obtained, (besides in the usual moist way, by dissolving cyanide of zinc in the alkaline cyanides,) by mixing the alkaline cyanides with carbonate, or any other salt of the oxide of zinc, as long as the cyanide of zinc is redissolved, upon which the double salt is obtained on evaporation, at least, as far as may be concluded from the action with cyanide of potassium. Caustic ammonia dissolves cyanide of zinc, and soon deposits 
the double salt. The double salt of barytes cannot be obtained by precipitating a solution of cyanide of zinc-potassium with acetate of barytes. It gives a white precipitate, insoluble, or nearly so, which contains barytes, with evolution of a strong smell of prussic acid. A corresponding combination with oxide of lead was obtained on precipitating cyanide of zinc-potassium with acetate of lead. It forms a white powder. Acetic acid removes the lead, leaving cyanide of zinc behind. The compound was not analysed, but regarded as $\mathrm{Zn} \mathbf{C y}+\dot{\mathrm{P}} \mathrm{b}$. This kind of combination of a cyanide with an oxide of another metal will be new and remarkable, should it be confirmed. Cyanide of zinc-magnesium could not be prepared ; the cyanogen is decomposed during evaporation, and a brown substance is deposited.-(Bers. Jahresber. vol. xx. part ii. p. 153.)

\section{On the Stibio- and Arsenio-Sulphurets.}

Persulphuret of antimony, $\mathrm{Sb}^{2} \mathrm{~S}^{5}$, combines with basic sulphurets to form very peculiar crystallizable salts, of which, however, only the sodium and potassium compounds have been ex. amined. Dr. Rammelsberg has published a memoir on the subject. Some chemists consider $\mathrm{Sb}^{2} \mathrm{~S}^{5}$ as a mixture of $\mathrm{Sb}^{2} \mathrm{~S}^{3}+\mathrm{S}^{2}$, because it is decomposed into these elements by boiling with oil of turpentine; its power, however, of forming characteristic salts, speaks for its being a determinate compound. [A fact in favour of its being a determinate sulphuret is, that when boiled with caustic soda, stibio-persulphuret of sodium and antimoniate of soda are formed, but no hyposulphite; on the other hand, the two atoms of sulphur may be driven out at a temperature by which sulphur boils; they may also be extracted by sulphuret of carbon.] (Mitscherlich, Poggendorff's Annalen, xlix. p. 412.)

The stibio-persulphurets may be formed in several ways. Those with the bases of the alkaline and earthy metals are soluble in water, and are either colourless or yellow; the insoluble salts are of various colours. The soluble sulphurets are decomposed by carbonic acid; the insoluble ones are often very difficult of decomposition.

The stibio-persulphuret of potassium is deliquescent; its formula is $3 \mathrm{~K} \mathrm{~S}+\mathrm{Sb}^{2} \mathrm{~S}^{5}+9 \mathrm{H}^{2} \mathrm{O}$, or $\dot{\mathrm{K}}^{3} \underline{\mathrm{S}} \dot{\mathrm{b}}+9 \underline{\dot{\mathrm{H}}}$. When sulphuretted hydrogen is passed through a solution of the neutral antimoniate of potash, persulphuret of antimony is thrown down, and the above-mentioned stibio-sulphuret remains in solution. Persulphuret of antimony loses its colour when treated with a solution of caustic potash; it dissolves, 


\section{Notices of the Labours of Continental Chemists.}

and at the same time a heavy white powder is formed; this is bin-antimoniate of potassa, $\dot{\mathrm{K}} \ddot{\mathrm{S} \dot{b}}+6 \dot{\mathrm{H}}$. If the solution be evaporated to a certain point, and then allowed to cool, a colourless salt separates in long acicular crystals; they are not deliquescent, but soon become covered with a brown substance. They are soluble in boiling water, but decomposed by cold water, by which part is dissolved, and antimoniate of potash remains behind. This is a compound of the stibiopersulphuret with antimoniate of potash. Its formula is $\left(3 \mathrm{~K} \mathrm{~S}+\mathrm{Sb}^{2} \mathrm{~S}^{5}+9 \mathrm{H}^{2} \mathrm{O}\right)+\left(\mathrm{KO}+\mathrm{Sb}^{2} \mathrm{O}^{5}+\mathrm{H}^{2} \mathrm{O}\right)$, or $\left(\dot{\mathrm{K}}^{3} \underline{\mathrm{S}} \underline{\mathrm{b}}+9 \underline{\mathrm{H}}\right)+(\dot{\mathrm{K}} \ddot{\ddot{\mathrm{S}} \dot{\mathrm{b}}}+\dot{\mathrm{H}})$. With soda no such salt can be obtained.

Stibio-sulphuret of Sodium.-Schlippe's salt crystallizes in tetrahedrons; subordinate are the faces of the second tetrahedron, dodecahedron, and tetratrishexahedron $\left(a: \frac{1}{2} a \propto a\right)$. The solution of this salt, by exposure to the air, deposits a reddish-brown powder: in the solution are contained carbonate and hyposulphite of soda. As to the formula of this salt there is some degree of uncertainty. Different formulæ


$+12 \dot{\mathrm{H}}$; Schlippe's, $\mathrm{Na}^{3} \underline{\mathrm{S} b}+20 \underline{\dot{H}}$. Rammelsberg found $\hat{\mathrm{Na}} \mathrm{a}^{3} \mathrm{~S} \dot{\mathrm{S}} \mathrm{b}+18 \dot{\mathrm{H}}$.

The barium salt can be obtained crystallized; its formula is $\dot{\mathrm{Ba}} \mathbf{a}^{3} \ddot{\mathrm{S}}+6 \dot{\mathrm{H}}$.

The ammonium, strontium, calcium and magnesium salts do not crystallize; they all, however, contain three atoms of basic sulphuret.

To obtain the pure metallic stibio-sulphurets, the solutions of the metallic salts must be added gradually to an excess of the alkaline stibio-sulphuret.

The silver, lead and copper salts, obtained in this manner, have the formulæ $\dot{A}^{3} \mathrm{~S}^{3}, \mathrm{~Pb}^{3} \stackrel{\mathrm{S}}{\mathrm{S}}, \mathrm{Cu}^{3} \mathrm{Sb}$. When the silver salt is heated sulphur is given off, and a substance remains having the formula $\hat{\mathrm{A}}^{3}{ }^{3} \mathrm{~S} \dot{\mathrm{b}}$, the same as red silver; by heating the lead compound, $\stackrel{\mathrm{P}}{\mathrm{b}} \mathrm{b}^{3} \mathrm{~S} \dot{\mathrm{b}}$ is obtained; this is the composition of Boulangerite. With corrosive sublimate the salt

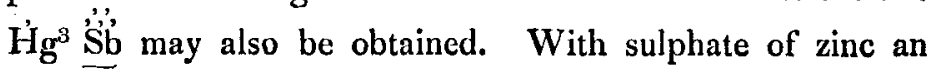


orange-coloured body is formed; its composition is $\mathrm{Zn}^{3} \underline{\mathrm{S}}$ $+\dot{\mathbf{Z}}$.

When the alkaline stibio-sulphuret is added to an excess of the metallic salt, and the whole boiled for some time, a totally different kind of salt is produced. By caustic potash these salts are decomposed into metallic sulphurets and antimonic acid. The silver salt contains $\mathrm{Ag}^{8} \mathrm{~S}^{8} \mathrm{Sb}^{2} \mathrm{O}^{5}$; it may be either $\dot{A} g^{3} \underline{\dddot{S}} \dot{b}+5 \dot{A} g$, or $8 \dot{A} g+\ddot{S} \dot{b}$. The lead and copper salts have the same constitution. With chloride of mercury a white precipitate is obtained; its composition is $\dot{\mathrm{H} g} \mathrm{~g}^{3} \ddot{\mathrm{S}} \dot{b}+3 \mathrm{Hg} \mathrm{Cl}^{2}+3 \dot{\mathrm{H} g}$.

When arsenio-sulphuret of sodium is added to an excess of sulphate of copper, and the whole boiled, the black insoluble substance which is formed is sulphuret of copper, $\mathrm{Cu} \mathbf{S}$, and in the solution is arsenic acid, containing the whole of the employed arsenic. It is therefore probable that these above-mentioned salts are compounds of the metallic sulphurets with antimonic acid. (Poggendorff's Annalen, lii. p. 193-242.)

XL. Meteorological Summary of the Weather at Montreal, Province of Canada, in Lat. $45^{\circ} 30^{\prime}$ N., Long. $73^{\circ} 22^{\prime} W$., from Registers kept (by J. S. MeCond, Associate Member of the London Meteorological Society, Member of the Natural History Society of Montreal, Corresponding Member of the Literary and Historical Society, Quebec, and Albany Institute, New York,) for five years, from 1836 to 1840 inclusive*.

\begin{tabular}{|c|c|c|c|c|}
\hline \multicolumn{5}{|c|}{ TEM PERATURE. } \\
\hline \multicolumn{5}{|c|}{ ANNUAL TEMPERATURE. } \\
\hline & Mean Temp. & Max. Temp. & Min. Temp. & Range. \\
\hline $\begin{array}{l}1836 . \\
1837 . \\
1838 . \\
1839 . \\
1840 .\end{array}$ & $\begin{array}{l}40 \cdot 43 \\
41 \cdot 22 \\
41 \cdot 58 \\
44 \cdot 07 \\
44 \cdot 29\end{array}$ & $\begin{array}{l}90 \cdot 00 \\
90 \cdot 00 \\
90 \cdot 00 \\
89 \cdot 00 \\
91 \cdot 00\end{array}$ & $\begin{array}{l}-19.00 \\
-18.00 \\
-13.00 \\
-18.00 \\
-14.50\end{array}$ & $\begin{array}{l}109 \cdot 00 \\
108 \cdot 00 \\
103 \cdot 00 \\
109 \cdot 00 \\
105 \cdot 50\end{array}$ \\
\hline Mean. & $42 \cdot 31$ & 90.00 & $-16 \cdot 50$ & $106 \cdot 90$ \\
\hline
\end{tabular}

* Reprinted from a table privately distributed by the author, communi. cated by Dr. Daubeny. 